\title{
Effect of Moisture on Trichoderma Conidia Production on Corn and Wheat Bran by Solid State Fermentation
}

\author{
Rosane S. Cavalcante • Helder L. S. Lima • \\ Gustavo A. S. Pinto • Carlos A. T. Gava • \\ Sueli Rodrigues
}

Received: 24 August 2007 / Accepted: 24 October 2007 / Published online: 21 November 2007

(C) Springer Science + Business Media, LLC 2007

\begin{abstract}
In the present work, the use of low-cost substrates to produce Trichoderma spores was evaluated. Rice, corn bran, and wheat bran were used as solid substrate to grow Trichoderma harzanium sp., Trichoderma viride sp., Trichoderma koningii sp., and Trichoderma polysporum sp. No external nutrient sources were added to the solid substrate that was only moisturized with deonized water, sterilized, inoculated, and cultivated at $30{ }^{\circ} \mathrm{C}$ for 7 days. Wheat bran showed to be the most suitable substrate to produce Trichoderma spores for all strains that were evaluated. High spore counts were obtained for $T$. harzianum sp. $\left(28.30 \times 10^{8} / \mathrm{gds}\right)$ and T. viride sp. $\left(24.10 \times 10^{8}\right.$ spores $\left./ \mathrm{gds}\right)$.
\end{abstract}

Keywords Entomopathogenic fungi · Conidia .

Low-cost substrates

\section{Introduction}

In the recent years, the environmental contamination caused by excessive use of chemical pesticides increased the

\author{
R. S. Cavalcante $\cdot$ H. L. S. Lima $\cdot$ S. Rodrigues $(\bowtie)$ \\ Depto de tecnologia de alimentos-UFC, \\ Universidade Federal do Ceará, \\ Caixa Postal 12168, CEP, \\ 60021-270 Fortaleza, CE, Brazil \\ e-mail: sueli@ufc.br \\ G. A. S. Pinto \\ Embrapa Agroindústria Tropical, \\ Rua Dra. Sara Mesquita 2270, Pici, CEP, \\ 60511-110 Fortaleza, CE, Brazil \\ C. A. T. Gava \\ Embrapa Semi-árido, \\ Caixa Postal 23 CEP, \\ 56302-970 Petrolina, PE, Brazil
}

interest in integrated pest management, where chemical pesticides are substituted by biopesticides to control plant pests and plant diseases. Trichoderma-based biocontrol agents (BCAs) possess better ability to promote plant growth and soil remediation activity compared to their counterparts (virus, bacteria, nematodes, and protozoa; Harman et al. 1993; Esposito and da Silva 1998). Their capability to synthesize antagonistic compounds (proteins, enzymes, and antibiotics) and micro-nutrients (vitamins, hormones, and minerals) enhance their biocontrol activity. Like other fungal BCAs, conidial mass of Trichoderma is the most proficient propagule, which tolerates downstream processing (e.g., air drying; Amsellem et al. 1999). Despite the advantages, mass production of Trichoderma BCAs is less prevalent, owing to high-cost raw materials like Mendel's medium, molasses, corn steep liquor, and other (Verma et al. 2005).

Trichoderma spp. have gained wide acceptance as effective BCAs against several commercial phytopathogens (Whipps and Lumsden 2001). These antagonistic fungi are most common among fungal biocontrol agents because of their multiple BCA characteristics, namely, antagonism and plant-growth stimulation (Punja and Utkhede 2003). Thus, mass-scale production of Trichoderma spp. would have great potential for commercial use. Micropropagules of Trichoderma spp. in the form of conidia are preferred over chlamydospores and mycelial biomass because of the viability and stability in field application (Amsellem et al. 1999). Therefore, there are several BCA products of Trichoderma spp. in the market containing conidia of Trichoderma spp. as active ingredients. Multiple BCA action renders the production of Trichoderma spp. conidia of commercial and environmental interest. There is abundant literature on the use of conventional synthetic media like glucose, cellulose, soluble starch, and molasses to 
produce Trichoderma spp. (Lewis and Papavizas 1983; Gupta et al. 1997). However, the cost of these raw materials for commercial production of BCAs is one of the major limitations behind the restricted use. To overcome the cost limitation, many researchers have successfully used substrates like corn fiber dry mass (Vlaev et al. 1997), sewage sludge compost (Cotxarrera et al. 2002), and cranberry pomace (Zheng and Shetty 1998). Despite the use of alternate sources, the cost of production was still high, as these raw materials need to be supplemented by other nutrients (Verma et al. 2007).

The density of a pathogen population is one of the most important factors to trigger the initiation of an epizootic. High relative humidity is widely recognized as a critical factor for fungi reproduction (Boucias and Pendland 1998; Hajek and Eastburn 2001). Most entomophthoralean fungi require high humidity to produce spores.

Solid-state fermentation is a cost-effective system for sporulation of fungi. As such, the objectives of the present study comprises the elevation of the use of byproducts of the cereal industry (corn bran and wheat bran) as raw materials to produce Trichoderma sp. conidia without the need of the addition of nutrients ( $\mathrm{C}$ and $\mathrm{N}$ sources) to increase spore concentration.

\section{Materials and Methods}

\section{Microbial Strains}

Four Trichoderma species (T. harzianum, T. viride, T. konigii, and T. polysporum) were studied. These fungi belongs to the collection of Embrapa Semi-Arido (Petrolina, $\mathrm{PE}$, Brazil) and were kept in sterile distilled water at $4{ }^{\circ} \mathrm{C}$ for long-time storage. The species used in the present work were selected because they have presented entomopathogenicity against ordinary plagues that attack grapes and melons.

Table 1 Moisture and water activity of the rice and corn bran used as solid substrates

\begin{tabular}{lllllll}
\hline \multirow{2}{*}{ Run } & $\begin{array}{l}\text { Immersion } \\
\text { time }(\mathrm{min})\end{array}$ & Rice & & & \multicolumn{2}{l}{ Corn bran } \\
\cline { 3 - 4 } \cline { 6 - 7 } & & $\begin{array}{l}\text { Moisture } \\
(\%)\end{array}$ & $\begin{array}{l}\text { Water } \\
\text { activity }\end{array}$ & & $\begin{array}{l}\text { Moisture } \\
(\%)\end{array}$ & $\begin{array}{l}\text { Water } \\
\text { activity }\end{array}$ \\
\hline 1 & 30 & $34.81 \pm 0.16$ & 0.925 & & $47.22 \pm 0.48$ & 0.945 \\
2 & 40 & $34.33 \pm 0.91$ & 0.990 & & $50.43 \pm 0.95$ & 0.995 \\
3 & 50 & $35.22 \pm 0.96$ & 0.987 & & $51.50 \pm 0.88$ & 0.997 \\
4 & 60 & $35.00 \pm 1.20$ & 0.994 & & $49.95 \pm 3.53$ & 0.995 \\
5 & 70 & $33.86 \pm 0.90$ & 0.950 & & $44.02 \pm 1.20$ & 0.960 \\
\hline
\end{tabular}

Table 2 Moisture and water activity of wheat bran used as solid substrates

\begin{tabular}{lll}
\hline Wheat Bran & \\
\hline Added water $(\mathrm{ml})$ & Moisture (\%) & Water activity \\
16 & $36.43 \pm 0.50$ & 0.973 \\
20 & $39.72 \pm 0.12$ & 0.962 \\
60 & $63.04 \pm 0.16$ & 0.945 \\
80 & $68.41 \pm 0.08$ & 0.990 \\
100 & $73.13 \pm 0.31$ & 0.955 \\
\hline
\end{tabular}

\section{Substrate Preparation}

In this work, food industry by-products were used as solid substrate for microbial cultivation. The substrates used were wheat bran and corn bran. Rice was used as the control for each tested strain, as rice is the standard medium used to large-scale cultivation of these biocontrol pesticides by Embrapa Semi-arido Brazil. All substrates were purchased from the municipal market (Mercado São Sebastião, Fortaleza, CE, Brazil).

The humidification of rice and corn bran was carried out, immersing $40 \mathrm{~g}$ of each substrate in $80 \mathrm{ml}$ of distilled water for different times (Table 1). The humidification of wheat bran was obtained adding fixed amounts of water because of its instantaneous water absorption (Table 2). Fermentation was carried out without external nutrient addition. The substrates were sterilized at $121{ }^{\circ} \mathrm{C}\left(1.1 \mathrm{kgf} / \mathrm{cm}^{2}\right)$ for 15 min in a Phoenix autoclave model AV 50 (Phoenix do Brazil, Araraquara, SP, Brazil) and cooled down to room temperature before the inoculation, which was done until $24 \mathrm{~h}$ after sterilization.

Substrate moisture, in wet basis, was determined by drying a proper amount of the sterilized substrate, without microorganisms, till constant weight in an oven MA-035 (Marconi Equipamentos para Laboratório, Piracticaba, SP, Brazil) at $105{ }^{\circ} \mathrm{C}$ for $48 \mathrm{~h}$ according to the AOAC (1990) method. Water activity was determined by direct measure in an Aqualab-CX equipment (Aqualab model CX, Decagon Devices, Pullman, WA, USA). Water activity was determined at the incubation temperature $\left(30.0 \pm 0.5{ }^{\circ} \mathrm{C}\right)$. The sample temperature was controlled by an external circulating water bath TE 2500 (Tecnal Equipamentos para Laboratórios, Piracicaba, SP, Brazil).

\section{Microbial Activation and Conidia Production}

The strains were first activated in potato dextrose agar (PDA) slants and incubated for 7 days at $30{ }^{\circ} \mathrm{C}$ in a termostated incubator chamber with air cirulation (Solab Científica, Piracicaba, SP, Brazil). This period showed to be sufficient for fungi sporulation. After harvesting the conidia from the agar-slants by adding a suitable amount of Tween 
$80(0.01 \%, v / v)$ sterile solution, the solid substrates were inoculated with $1 \times 10^{6}$ spores to $40 \mathrm{~g}$ of the solid substrate disposed in $250 \mathrm{ml}$ Erlenmyers flasks covered with cotton plugs. The solid media was incubated for 7 days at $30^{\circ} \mathrm{C}$. After this period, the conidia were harvested by adding three portions of $50 \mathrm{ml}$ of $0.01 \%(v / v)$ sterile Tween 80 and counted in a Neubauer chamber. Results were expressed as conidia amount per gram of dry solid (conidia/gds). The conidia supported in the solid substrates were kept at $4{ }^{\circ} \mathrm{C}$ by 12 months, and the strain viability was evaluated by cultivation in PDA medium each 30 days.

The conidia viability was assessed by inoculating the stock culture in PDA medium and incubating for 5 days at $30{ }^{\circ} \mathrm{C}$. All the strains presented good viability for at least 6 months when stored at $4{ }^{\circ} \mathrm{C}$. All experimental runs were carried out in duplicate, and spores counting were done in triplicate. Results are expressed as mean $\pm \mathrm{SD}$.

\section{Results and Discussions}

According to the results presented in Tables 1 and 2, the water activity of all solid substrates ranged from 0.925 to 0.994. Comparing the moistening treatments and the final moisture of the solid substrates used in the present work, it is possible to state that rice presented the lowest ability to absorb water, as rice presented the narrowest moisture range, followed by corn bran. Rice and corn were immersed in water for several different times to absorb water; the saturation of the solid matrix was easily reached as presented in Table 1. The maximum water absorption capacity depends on several factors such as solid matrix structure and superficial area, as well as the ability of hydrogen-bond formation sites, among other factors (Pandey et al. 2001). Rice and corn were immersed for sufficient time to reach their water saturation. Wheat presented a higher ability of water absorption. The use of lower moistures inhibited fungi growth.

The water activity isotherm is a sigmoidal curve, and at high values of aw ( $>0.9)$, some minor variations on water activity are expected. Water activity in solids is subject to such variations because of the nonhomogeneity of the system. Some variations in the solid matrix are expected because the granules are not totally symmetric and uniform. Because of the nonhomogeneity of the solid particles, minor changes in the water activity are expected especially after the sterilization. This variation can be higher considering the presence of broken solids with different sizes and superficial area. Wheat bran presented the largest moisture range and a good ability to absorb water. The maximum water adsorption was also reached for wheat bran $(73.13 \pm 0.31)$, as the addition of more water caused the substrate flooding, making it inappropriate to solid-state fermentation.
Table 3 presents the spores produced by each species under study for each experimental run. According to the results presented in Table 3, for all studied Trichoderma species, wheat bran was the best-studied medium for spore production. The optimum moisture content of the used wheat bran was $68.41 \pm 0.08 \%$. The increase of moisture to $73.13 \pm$ $0.31 \%$ strongly decreased the spore amount produced by all studied species. Using wheat bran as substrate strongly enhanced the spore production of T. harzianum and T. viride. For these two species, the amount of spores produced was more than four times the number of spores produced using rice at the best moisture condition. On the other hand, the spore amount produced by $T$. koningii did not change significantly considering the three evaluated substrates. Corn bran was not a suitable substrate for spore production of $T$. polysporum, and wheat bran enhanced the spore production of this specie by $75 \%$ compared to the production using rice.

Results presented in Table 3 clearly show that water activity and moisture of the solid-substrate are not the only factor that affected Trichoderma conidia production. Despite runs 1 and 2, using wheat bran as solid substrate was carried out with similar moisture of rice, no fungi growth, and spore formation was observed in these runs. Thus, although higher amounts of spores were obtained using wheat bran, significant amounts were only observed at higher moisture contents $(>60 \%)$. Similar results were

Table 3 Spores produced using rice, corn bran, and wheat bran as solid substrates

\begin{tabular}{|c|c|c|c|c|}
\hline \multirow[t]{2}{*}{ Strain } & \multirow[t]{2}{*}{ Run } & \multirow{2}{*}{$\begin{array}{l}\text { Rice } \\
\text { Spores } \times \\
10^{8} / \text { gds }\end{array}$} & \multirow{2}{*}{$\begin{array}{l}\text { Corn bran } \\
\text { Spores } \times \\
10^{8} / \mathrm{gds}\end{array}$} & \multirow{2}{*}{$\begin{array}{l}\text { Wheat bran } \\
\text { Spores } \times \\
10^{8} / \text { gds }\end{array}$} \\
\hline & & & & \\
\hline \multirow{5}{*}{$\begin{array}{l}\text { Trichoderma } \\
\text { harzianum sp. }\end{array}$} & 1 & $2.20 \pm 0.05$ & $5.00 \pm 0.20$ & $\mathrm{Nd}$ \\
\hline & 2 & $5.80 \pm 0.15$ & $7.45 \pm 0.15$ & $\mathrm{Nd}$ \\
\hline & 3 & $2.73 \pm 0.13$ & $2.30 \pm 0.09$ & $5.10 \pm 0.09$ \\
\hline & 4 & $2.13 \pm 0.07$ & \pm 0.12 & $28.30 \pm 0.06$ \\
\hline & 5 & $2.58 \pm 0.10$ & $3.08 \pm .15$ & $6.55 \pm 1.23$ \\
\hline \multirow{5}{*}{$\begin{array}{l}\text { Trichoderma } \\
\text { viride sp. }\end{array}$} & 1 & $5.78 \pm 0.15$ & $2.48 \pm 0.09$ & $\mathrm{Nd}$ \\
\hline & 2 & $1.80 \pm 0.15$ & $6.88 \pm 0.25$ & $\mathrm{Nd}$ \\
\hline & 3 & $2.50 \pm 0.09$ & $4.93 \pm 0.16$ & $1.90 \pm 0.03$ \\
\hline & 4 & $5.03 \pm 0.25$ & $6.28 \pm 0.20$ & $24.10 \pm 0.52$ \\
\hline & 5 & $2.68 \pm 0.16$ & $2.33 \pm 0.06$ & $3.25 \pm 0.10$ \\
\hline Trichoderma & 1 & $5.78 \pm 0.23$ & $1.38 \pm 0.07$ & $\mathrm{Nd}$ \\
\hline \multirow{4}{*}{ koningii sp. } & 2 & $2.31 \pm .11$ & $1.13 \pm 0.06$ & $\mathrm{Nd}$ \\
\hline & 3 & $3.71 \pm 0.15$ & $5.38 \pm 0.17$ & $2.85 \pm 0.07$ \\
\hline & 4 & $4.13 \pm 0.20$ & $6.10 \pm 0.22$ & $8.85 \pm 0.13$ \\
\hline & 5 & $2.67 \pm 0.10$ & $1.95 \pm 0.10$ & $3.10 \pm 0.06$ \\
\hline \multirow{5}{*}{$\begin{array}{l}\text { Trichoderma } \\
\text { polysporum sp. }\end{array}$} & 1 & $4.00 \pm 0.10$ & $0.28 \pm 0.01$ & $\mathrm{Nd}$ \\
\hline & 2 & $2.63 \pm 0.05$ & $2.60 \pm 0.10$ & $\mathrm{Nd}$ \\
\hline & 3 & $5.03 \pm 0.11$ & $1.98 \pm 0.09$ & $1.90 \pm 0.02$ \\
\hline & 4 & $2.18 \pm 0.05$ & $1.80 \pm 0.06$ & $6.50 \pm 0.10$ \\
\hline & 5 & $1.45 \pm 0.03$ & $0.18 \pm 0.05$ & $1.75 \pm 0.05$ \\
\hline
\end{tabular}

Values in italics indicate the best production of each run nd Nondetected 
obtained for wheat bran with $63.04 \pm 0.16$ and rice with $34.33 \pm 0.91$ for $T$. harzanium, $T$. viride and $T$. koningii. Other correlations were not possible to be made.

Besides moisture and water activity, solid state fermentation is also affected by the solid composition and structure, as well as by the cultivated strain. The availability and accessibility of the nutrients in the solid matrix depends on the solid porosity and structure that may be affected by the moisture and sterilization. Moisturizing was carried out by immersing the solid in water and depending on the immersion time, some nutrients might have solubilized and lost to the liquid medium, leading to poor substrate as for rice and corn. The results presented herein suggested, especially for rice and corn, that the immersion time can affect the solid structure and the nutrient availability, even resulting in similar moisture and water activity, making the optimum sporulation condition for each strain different. As mentioned before, the solid matrix structure also affects the solid-state fermentation because the fungi can penetrate the solid in different ways because of its porosity and tortuosity. Water distribution in the solids can also be affected by its structure. Fermentation with rice and wheat bran where carried out at their maximum moisture content.

Many papers on the use of BCA such as Trichoderma sp. have been published. However, few studies were found regarding spore production, all of them considering submerged fermentation (Verma et al. 2005, 2006, 2007; Jakubikova et al. 2006; Jin et al. 1996). The results for conidia production in submerged fermentation were expressed as colony-forming unit per milliliter $(\mathrm{CFU} / \mathrm{ml})$ after incubation on agar; thus, the results cannot be directly compared. For solid state fermentation, some works on conidia production were published (Zhao and Shamon 2006; Leland et al. 2005; Essien et al. 2005; Delalibera Jr. 2005; Larena et al. 2004; Jones et al. 2004; Chen et al. 2005; Tewari and Bhanu 2004). Among them, only one has addressed Trichoderma conidia production (Tewari and Bhanu 2004). Even in this work, the results were reported as CFU instead of spore amount, making directly comparison not valid.

\section{Conclusion}

Wheat bran showed to be a suitable substrate for spore production of $T$. harzianum, T. viride, T. koningii, and $T$. polysporum. For all studied species, the use of wheat bran increased the production of spore. However, the enhancement was extremely high for $T$. harzianum and $T$. viride. No nutritional supplementation needed high spores production.

The use of wheat bran is interesting because its manipulation is easier than corn bran and rice because of its low starch content and rapid water absorption.
Acknowledgment To Conselho Nacional de Desenvolvimento Cientifico e Tecnológico-CNPq for the financial support.

\section{References}

Amsellem, Z., Zidack, N. K., Quimby, P. C., Jr., \& Gressel, J. (1999). Long-term dry preservation of viable mycelia of two mycoherbicidal organisms. Crop Protection, 18, 643-649.

AOAC (1990). Official methods of analysis. Washington: Association of Official Analytical Chemists.

Boucias, D. G., \& Pendland, J. C. (1998). Principles of insect pathology. Boston: Kluwer.

Chen, X., Li, Y., Du, G., \& Chen, J. (2005). Application of response surface methodology in medium optimization for spore production of Coniothyrium minitans in solid-state fermentation. World Journal of Microbiology and Biotechnology, 21, 593-599.

Cotxarrera, L., Trillas-Gay, M. I., Steinberg, C., \& Alabouvette, C. (2002). Use of sewage sludge compost and Trichoderma asperellum isolates to suppress Fusarium wilt of tomato. Soil Biology and Biochemistry, 34, 467-476.

Delalibera, I., Jr., Demétrio, C. G. B., Mably, B. F. J., \& Hajek, A. E. (2006). Effect of relative humidity and origin of isolates of Neozygtes tanajoae (Zygomycetes: Entomophthorales) on production of conidia from cassava green mite, Mononychellus tanajoa (Acari: Tetranychide), cadavers. Biological Control, 39, 489-496.

Esposito, E., \& da Silva, M. (1998). Systematics and environmental application of the genus Trichoderma. Critical Reviews on Microbiology, 24, 89-98.

Essien, J. P., Akpan, E. J., \& Essien, E. P. (2005). Studies on growth and biomass production using waste banana peel. Bioresource Technology, 96, 1451-1456.

Gupta, R., Saxena, R. K., \& Goel, S. (1997). Short communication: Photoinduced sporulation in Trichoderma harzianum-An experimental approach to primary events. World Journal of Microbiology and Biotechnology, 13, 249-250.

Hajek, A. E., \& Eastburn, C. C. (2001). Effect of host insects on activation of Entomophaga maimaiga resting spores. Journal of Invertebrate Pathology, 77, 290-291.

Harman, G. E., Haynes, C. K., Lorito, M., Broadway, R. M., diPietro, A., Peterbauer, C., et al. (1993). Chitinolytic enzymes of Trichoderma harzianum: Purification of chitobiosidase and endochitinase. Phytopathology, 83, 313-318.

Jakubikova, L., Farkas, V., Kolarova, N., \& Nemcovic, M. (2006). Conidiation of Trichoderma atroviridie isolate during submerged cultivation in a laboratory stirred-tabk fermenter. Folia Microbiologica, 51, 209-213.

Jin, X., Taylor, A. G., \& Harman, G. E. (1996). Development of media and automated liquid fermentation methods to produce desiccationtolerant propagules of Trichoderma harzanium. Biological Control, 7, 267-274.

Jones, E. E., Weber, F. J., Oostra, J., Rinzema, A., Lead, A., \& Whipps, J. M. (2004). Conidial quality of the biocontrol agent Coniothyrium minitans produced by solid-state cultivation packed-bed reactor. Enzyme and Microbial Technology, 34, 196-207.

Larena, I., De Cal, A., \& Melgarejo, P. (2004). Solid substrate production of Epicoccum nigrum conidia for biological control of brown rot on stone fruit. International Journal of Food Microbiology, 94, 161-167.

Leland, J. E., McGuire, M. R., Grace, J. A., Jaronski, S. T., Ulloa, M., Park, Y. H., et al. (2005). Strain selection of fungal entomopathogen, 
Beauveria bassiana, for control of plant bugs (Lygus spp.) (Heteroptera: Miridae). Biological Control, 35, 104-114.

Lewis, J. A., \& Papavizas, G. C. (1983). Production of chlamydospores and conidia by Trichoderma spp. in liquid and solid growth media. Soil Biology and Biochemistry, 15, 351-357.

Pandey, A., Soccol, C. R., Rodriguez-Leon, J. A., \& Poonan, N. (2001). Solid-state fermentation in biotechnology: Fundamentals and applications (p. 2201st ed.). New Delhi: Asiatech.

Punja, Z. K., \& Utkhede, R. S. (2003). Using fungi and yeasts to manage vegetable crop diseases. Trends in Biotechnology, 21, 400-407.

Tewari, L., \& Bhanu, C. (2004). Evaluation of agro-industrial wastes for conidia bases incoulum production of bio-control agent: Trichoderma harzanium. Journal of Scientific and Industrial Research, 6, 807-812.

Verma, M., Satinder, K. B., Tyagi, R. D., Surampalli, R. Y., \& Valeró, J. R. (2005). Wastewater as potential for antagonistic fungus (Trichoderma sp): Role of pre-treatment and solids concentration. Water Reaserch, 39, 3587-3596.

Verma, M., Satinder, K. B., Tyagi, R. D., Surampalli, R. Y., \& Valeró, J. R. (2006). Dissolved oxygen as principal parameter of conidia production of biocontrol fungi Trichoderma viride in non newtonina wastewater. Journal of Industrial Microbiology, 33, 941-952.

Verma, M., Satinder, K. B., Tyagi, R. D., Surampalli, R. Y., \& Valeró, J. R. (2007). Starch industry wastewater as substrate for antagonist, Trichoderma viride production. Bioresource Technology, 98, 2154-2162.

Vlaev, S. D., Djejeva, G., Raykovska, V., \& Schugerl, K. (1997). Cellulase production by Trichoderma sp. Grown on corn fibre substrate. Process Biochemistry, 32, 561-565.

Whipps, J. M., \& Lumsden, R. D. (2001). Commercial use of fungi as plant disease biological control agents: Status and prospects. In T. Butt, C. Jackson, \& N. Magan (Eds.) Fungal biocontrol agents: progress, problems and potential (pp. 9-22). Wallingford: CABI Publishing.

Zhao, S., \& Shamon, S. F. (2006). The effect of culture media, solid substrates, and relative humidity on growth, sproulation and conidial discharge of Valdensinia heterodoxa. Mycological Research, 110, 1340-1346.

Zheng, Z., \& Shetty, K. (1998). Cranberry processing waste for solid state fungal inoculant production. Process Biochemistry, 3, 323-329. 